\title{
THE FORMATIVE ASSESSMENTS FOR BUILDING DRAWINGS
}

\author{
G. W. T. C. KANDAMBY
}

Division of Civil Engineering Technology, Institute of Technology, University of Moratuwa, Sri Lanka

\begin{abstract}
Manual drawing for building components was practiced by the students throughout the year under the module of building construction and draftsmanship aiming to acquire knowledge of constructing building components and to develop drafting skills of students. This practice lasted for years and the majority of students were able to get just pass marks for the assigned drawings in formative assessments. Therefore, it was decided to study the effectiveness of this practice for the development of skill on drafting, students' learning and finally how it supported for students to get marks at the end examination. Students' performances for both formative assessments and summative assessments were collected based on the years2015, 2016 and 2017 and questionnaire survey was conducted in 2017 to find the students perception of this practice. It is found that students have developed skill for drafting, but majority of students were not able to get high marks at the end examination. When comparing the time spent by both students and instructors, the results are not at a satisfactory level. Therefore new development on this practice is required for better results for students' learning and to keep good performance on manual drawing.
\end{abstract}

KEYWORDS: Manual Drawing, Building Elements, Students' Learning \& Formative Assessment

Received: Dec 03, 2018; Accepted: Dec 25, 2018; Published: Jan 25, 2019; Paper Id.: IJCSEIERDFEB20194

\section{INTRODUCTION}

Building construction and draftsmanship was one of the modules in the first year of the National Diploma in Technology (NDT) programme till 2017 aiming to give knowledge for students to describe the building elements, their functions and method of construction or fabrication, selection of building materials and develop skill in drafting building elements. While delivering the lectures to cover the learning outcomes of the module, formative assessments were conducted in drawing room as practical classes for drafting building elements. Students were assessed through the completed drawings at the end of each drawing as one of the requirements of satisfactory completion of practical classes. Students had to get through all assigned drawings to achieve the performance for satisfactory completion of practical classes. This process acted as one of the method of formative assessment for encouraging students' learning. Total module delivery was three hours drawing practical and two hours lecture per week to complete 30 week period in a year. Numbers of the students in a batch were about 80 and four instructors were assigned to supervise students' deskwork and support them to complete the given drawing within the allotted time. Attending drawing work is compulsory and students have to show more than $70 \%$ of attendance for these practical classes. It was noticed that almost all students were keen to maintain good attendance as there were no other way to catch the missed work. This module was delivered through two hour lectures per week where students carried out sketching while collecting information for construction of building elements. In addition, copies of details of the respective building elements were given for them to understand and draw. Author was the lecturer in charge of this module and participated as an instructor for this practical drawing classes, 
understand the students' problems and arrange the lecture series with respect to the progress of the drawing classes were maintained satisfactorily. Lecture for the respective building element had to be completed for them to start the drawing work on that building element.

\section{Practice of Manual Drawings}

Under the practical schedule, students were assigned eight drawings starting with simple drawings for practicing symbols of building materials, drawing lines and lettering using drawing board, T- ruler, set squares and other drawing tools. After completing the day's work, drawings were collected and kept in the drawing room for continuing the next day. It was a continued practical work and three or four days ( 9 to 12 hours) were given for completing one drawing. Instructors marked the completed drawings by highlighting the mistakes on the drawing sheet using pencils and allowed students to attend the correction as homework. Incorrect areas were erased, attended all corrections and resubmitted the same drawing in the following drawing class. Weak students had to attend the corrections in several times by getting instructions from the instructors. In this process of teaching, instructors received good training to manage this drawing practical, well in future batches and to understand the students' weaknesses in drawing skills. As a result, identified mistakes were discussed in detail during the lecture class for the whole group in order to minimize the correction period. Students received good feedbacks for completion of eight drawings one by one throughout the year. Their performances on each completed drawings were recorded in the register by giving grades $\mathrm{B}^{+}$to $\mathrm{C}^{-}$or some occasions $\mathrm{R}$ (Repeat). Students were engaged in this task till they completed all drawings to the satisfactory level. Development of drawing skills had supported students to attend compulsory two questions in their final end examination. Since author has experience in delivering this module with drawing practical for about four years period, following issues were identified.

- Students did not spend time effectively either attending new drawing work or correction work.

- Students wished to attend the corrections at home.

- Because of the corrections which were allowed to do at home, students skip other classes in order to complete the corrections. Action was taken to hand over the correction drawings on Fridays and resubmission on coming Mondays to avoid this situation.

- It was noted that students spent more time for drawing questions (two questions) without attending other questions in the end examination. Then they were able to get very less total marks at the end examination.

- At the end of the year, weak students had to attend more than one drawing unless they attend the corrections properly.

\section{OBJECTIVES OF THE STUDY}

The objectives of this study are to investigate and find;

- The effect of formative assessments conducted in drawing practical for students' learning.

- The effect of formative assessments to enhance high score in the yearend examination

- Students' perception on manual drawing, practicing and assessments. 


\section{LITERATURE REVIEW}

\section{Learning and Assessments in Manual Drawing}

Aim of delivering the module is to convey the expected information to the students for them to collect them and work on that to gain knowledge and skill resulting in learning to achieve the intended learning outcomes. Module of building construction and draftsmanship was aimed to acquire knowledge of construction of building components of a single storey building and develop drafting skill to illustrate the building components as manual drawings. Manual drawings were conducted as practical sessions in the classroom so that students engaged in drafting building components. Drawings of building components demonstrate the way of constructing in detail, including materials and methods. Drawing is one of the oldest forms of communication, to present ideas into lines and symbols, and it has been a useful tool for understanding that which cannot be understood by the use of verbal communications (Smith, 1997). Technical drawings have long been recognized as a powerful communications tool by professional engineers, scientists, mathematicians, statisticians, and other technical professionals. By learning the building construction module along with manual drawings help students to visualize the building works and understand the appropriate information to be conveyed in building engineering field. Drawing practical classes were conducted as formative assessments of this module to enable the student to practice drafting and learn the building engineering principles by getting support from the instructors. Instructors were able to monitor the students' deskwork, help them to improve their skill in drafting and provide information for learning the construction methods as expected in the learning outcomes. Some students have different attitudes towards learning. There has been an increasing tendency to seek to understand methods that are intended to guide the learning towards the goal that takes place during the learning process (William, 2011). Teachers can support students to process information by helping them to organize new information, link it to their existing knowledge and use memory aids to retrieve information (Eady\& Lockyer, 2013). Bloom was convinced that one to one tutorial instruction is the gold standard for education which would not be affordable for mass public education. Creating a situation and shaping it for appropriate learning is what successful teacher has learned to do effectively (Braskamp\&Ory, 1994). There were 80 students in the practical classroom, which was manageable in size by four instructors covering whole activities providing a comfortable learning environment. Effective teaching is not only delivering the factual material direct to the students for enhancing their knowledge, but also providing a good learning environment where students, play their role with active involvement in learning (Kandamby, 2017). There were eight drawings which had to be completed during the course of practicing classes and students needed to get through all drawing at the end of the year as a part of the summative assessment. Practice of assigned eight drawings acted as learning and assessment tool where students' performance was assessed for each drawing once it was completed. Through practice in classroom assessment, it is possible to understand and promote learning and increase the ability to help students themselves to become more effective, self-assessing, selfdirected learners (Thomas, \& Cross, 1993). What a student learns as a result of a particular sequence of instructional activities is impossible to predict and only through assessment it is possible to find whether a particular sequence of instructional activities has resulted for intended learning outcomes (Cotton, 1988). The assessment includes a wide range of methods for evaluating pupil performance and attainment, including formal testing and examinations, practical and oral assessment, classroom based assessment carried out by teachers (Gipps, 1994). Assessment as a part of classroom activities is a fundamental process required to promote learning (Jones, 2005). The appropriate assessment model inside the classroom is one that is designed to support the teaching and learning of important skills and concepts at both basic and higher levels (Buhagiar, 2007). Assessment is a process that includes four basic components such as measuring 
improvement over time, motivating students to study, evaluating the teaching methods and ranking the students' capabilities in relation to the whole group evaluation (Taghi, 2009). Purpose of classroom assessment is to improve the quality of student learning, not to provide evidence for evaluating or grading students. Assessment for learning has disseminated four interventions: questioning, feedback for marking, peer-and-self assessment and formative use of summative tests (Taras, 2010).

\section{Feedback for Manual Drawings}

The instructors gave feedback for individual students in the way of marking the corrections on each drawing sheet and gave a rating for their achievements. Information does not become a feedback unless it is provided within the system that can use that information to affect future performance (Wiliam, 2011). Students verified the corrections if required, identified their mistakes or errors, corrected them and submitted in the following day. It was a continuous process for presenting feedback for students' learning and encouraging them for active participation. One of the main reasons that one-to-one tutoring is so effective, is that the tutor is able to identify errors in the student's work immediately, and then provide clarification, and further follow-up if necessary (Guskey, 2010). It was noted that students showed good attendance throughout the year by attending their work to make the programme in success. Monitoring students' learning can be performed engaging in one-to-one contacts with students about their work, assigning, collecting, correcting work and recording scores and identifying gaps in their knowledge (Cotton, 1988). The collection of frequent feedback on students' learning, and the design of modest classroom experiments, teachers can learn much about how students learn and, how students respond to particular teaching approaches (Thomas, \& Cross, 1993). There are ways of obtaining feedbacks for both teaching and learning in higher education. The teacher can obtain the feedbacks for teaching from the respective group of students and students can get feedbacks for their learning from the teachers. Since the drawings are basically done with pencils, whatever the corrections marked on the drawing sheets using pencil can be erased by the students and attend the corrections as instructed. Instructors again check the drawings and give the rating or instruct to attend the correction till it is totally free from mistakes. The method adopted for giving feedback for each manual drawing is a time consuming task as one drawing has to be checked several times with the instructors. But students get a flow of instructions and feedback for each and every mistake they do while drafting the drawings. Feedback is an aspect of quality of assessment, what feedback is provided, how it is accepted by students and the extent to which it is integrated in future teaching and learning (Havnes, et al., 2012). Feedback is among the most critical influences on student learning. If it is directed at the right level, it can assist students to comprehend, engage or develop to process the information intended to be learned (Hattie \& Timperley, 2007). The evidence collected from these feedbacks is very useful for the teacher to study and understand the areas which need improvements in the delivery. Feedback needs to provide information specifically relating to the task or process of learning that fills a gap between what is understood and what is aimed to be understood (Sadler, 1989). Considerable research evidence is available to show that effective feedback leads to learning gain and has produced significant benefits in learning and achievement of knowledge and skills of education (Nicol \& MacfarlaneDeck, 2006). Effective classroom assessment method help to improve students' attendance, build good relationship with the teacher, encourage students for active participation and give required knowledge to the students specially to achieve high performance at end examination (Kandamby, 2017). When feedback is combined with effective instruction in classrooms, it can be very powerful in enhancing learning (Hattie, \& Timperley, 2007). 


\section{METHODOLOGY}

- Prevailed system of practicing drawings as formative assessments was studied by collecting relevant data from 2015 to 2017. In order to analyse the data as qualitative methodology, different ranges of the marked grades are combined as high level, middle level and lower level as follows. Marks in combined grades are in close range.

Higher level - Grades B+ and B

Middle level - Grades B- and C+

Lower level - Grades C and $\mathrm{C}^{-}$

- Students' performances of year end examinations were studied by collecting marks received by the students for two drawing questions from 2015 to 2017.

- A questionnaire survey was conducted in 2017, after students received their yearend results. Students were asked to give their preference for following two questions along with the appropriate reasons to analyze the students' perceptions on change of the prevailed system.

Question 1: Preference for assessing drawings separately without including in yearend examination

Question 2: Preference for assessing drawings while conducting drawing practical classes

\section{DATA COLLECTION}

Following information of manual building drawing were collected from the register for 2015, 2016 and 2017.

- A number of manual drawings and practiced time periods.

- Students' grades received for the completed drawings.

Marks received by students for drawing questions in the year end examinations in 2015, 2016 and 2017.

Students' perceptions on the given two questions explained in section 3 of the methodology.

\section{ANALYSIS}

\section{Formative Assessments}

There were eight drawings (D1 to D8) in all three years (2015, 2016 and 2017) completed by the students as coursework in 30 weeks period. Time spent for eight drawings in these three years is summarized in Table 1.

Table 1: Time Spent for Manual Drawings

\begin{tabular}{|c|c|c|c|c|c|c|c|c|c|c|}
\hline \multirow{2}{*}{ Year } & \multicolumn{10}{|c|}{ Hours Spent for Drawings } \\
\cline { 2 - 12 } & D1 & D2 & D3 & D4 & D5 & D6 & D7 & D8 & Extra & Total \\
\hline 2015 & 12 & 12 & & 12 & 15 & 12 & 12 & 9 & 3 & 87 \\
\hline 2016 & 15 & 12 & 12 & 12 & 12 & 9 & 9 & 6 & 3 & 90 \\
\hline 2017 & 15 & 9 & 9 & 12 & 9 & 9 & 9 & 6 & 3 & 81 \\
\hline
\end{tabular}


Table 2: Students' Performances in Formative Assessments

\begin{tabular}{|c|c|c|c|c|c|c|c|c|c|}
\hline \multirow{3}{*}{ Drawings } & \multicolumn{9}{|c|}{ Number of Students } \\
\cline { 2 - 11 } & \multicolumn{3}{|c|}{$\mathbf{2 0 1 5}$} & \multicolumn{3}{|c|}{$\mathbf{2 0 1 6}$} & \multicolumn{3}{c|}{$\mathbf{2 0 1 7}$} \\
\cline { 2 - 11 } & Higher & Middle & Lower & Higher & Middle & Lower & Higher & Middle & Lower \\
\hline D1 & 2 & 11 & 68 & 1 & 11 & 67 & 0 & 15 & 62 \\
\hline D2 & 0 & 9 & 72 & 0 & 14 & 65 & 2 & 23 & 52 \\
\hline D3 & 0 & 12 & 69 & 7 & 20 & 52 & 0 & 36 & 41 \\
\hline D4 & - & - & - & 3 & 15 & 61 & 0 & 38 & 39 \\
\hline D5 & 3 & 16 & 62 & 0 & 32 & 47 & 2 & 36 & 39 \\
\hline D6 & 1 & 22 & 58 & 0 & 23 & 56 & 2 & 39 & 36 \\
\hline D7 & 0 & 21 & 60 & 0 & 15 & 64 & 0 & 32 & 45 \\
\hline D8 & 1 & 11 & 69 & 2 & 17 & 60 & 5 & 51 & 21 \\
\hline Mode & 3 & 22 & 72 & 7 & 32 & 67 & 5 & 51 & 62 \\
\hline
\end{tabular}

Analysis of students' performances is considered as stated in methodology under higher, middle and lower levels for drawings from D1 to D8 and they are summarized in Table 2.

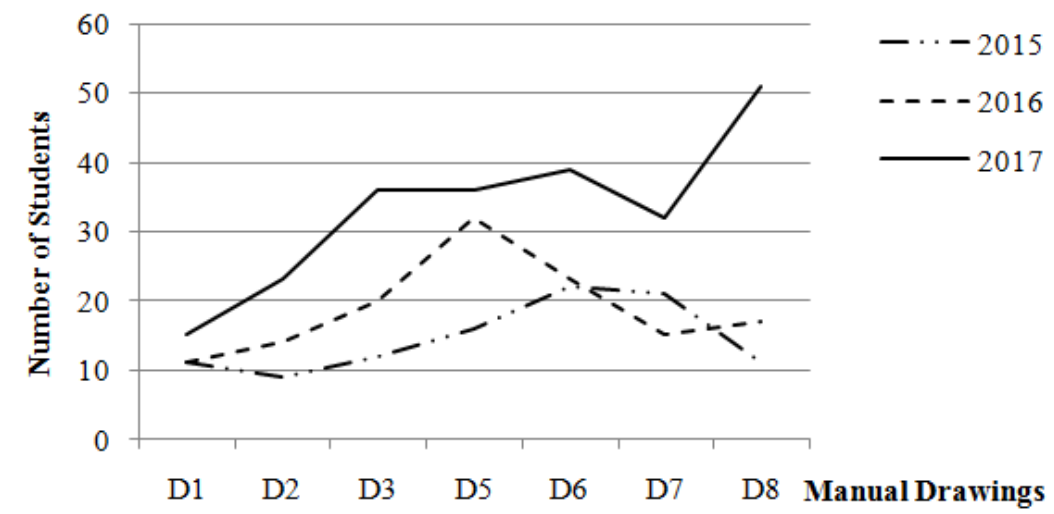

Figure 1: Middle Level Performance for Formative Assessments

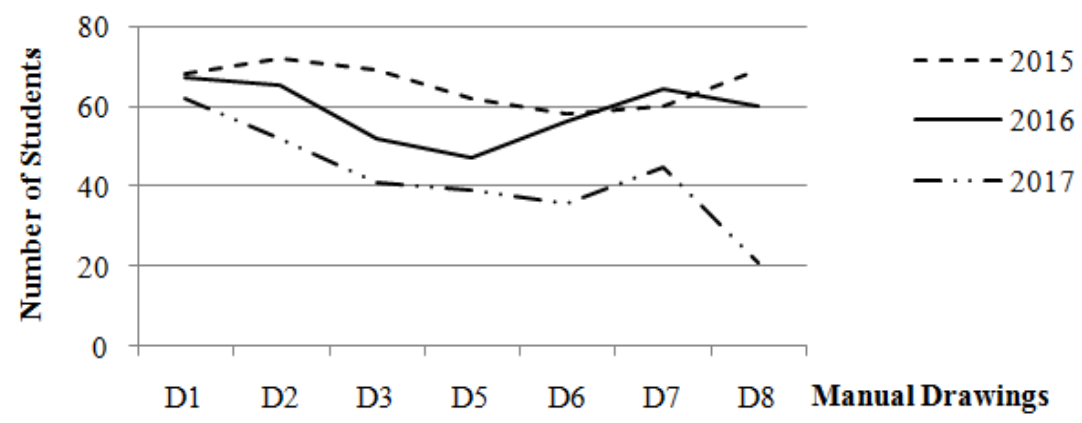

Figure 2: Lower Level Performance for Formative Assessments

Since D4 drawing was not practiced in 2015, it was removed from the total analysis. Students of 22, 32 and 51 have achieved performance for middle level in 2015, 2016 and 2017 respectively, whereas the performances in lower level in these three years are 72, 67 and 62. Students' distributions against their performances in both middle and lower levels are shown in Figure 1 and Figure 2.

\section{Summative Assessments}

There were two compulsory questions under the manual drawing area in which students were able to get marks out of 40. Marks received by the students for 2015, 2016 and 2017 are considered by converting the received marks out of 100. 
Table 3: Marks in \% under Five Number Summary

\begin{tabular}{|l|c|c|c|}
\hline & $\mathbf{2 0 1 5}$ & $\mathbf{2 0 1 6}$ & $\mathbf{2 0 1 7}$ \\
\hline Minimum & 13 & 25 & 15 \\
\hline Q1 & 28 & 43 & 45 \\
\hline Median & 35 & 55 & 63 \\
\hline Q3 & 47 & 68 & 73 \\
\hline Maximum & 75 & 88 & 90 \\
\hline
\end{tabular}

Variations of students' performances in the yearend examination are analyzed by considering the five number summary minimum, first quarter, median, third quarter and maximum marks of the said three years separately. Change in the performances through the above five number summary is plotted using boxplot to verify its improvement through these three years.

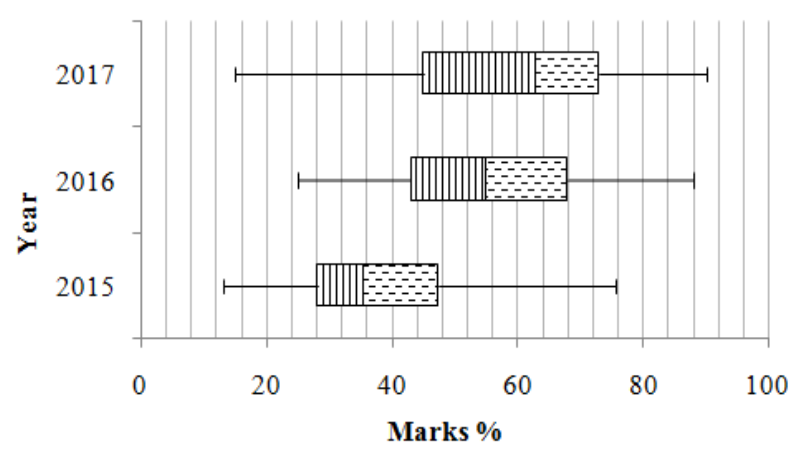

Figure 3: Boxplot for Summative Assessments

\section{Students' Perception for the Assessments}

Data was collected through questionnaire survey from students of 2017 in or order to find the students' perception of conducting assessment after completing all manual practicing in a classroom in the yearend examination. The reasons given by the students for the above preference were summarized in Table 5.

Table 4: Students' Perception on Manual Drawings

\begin{tabular}{|l|c|}
\hline \multicolumn{1}{|c|}{ Students Preference } & Population \% \\
\hline $\begin{array}{l}\text { 1. Assessing drawings separately } \\
\text { without including in yearend examination. }\end{array}$ & 71 \\
\hline $\begin{array}{l}\text { 2. Preference for assessing drawings } \\
\text { while conducting drawing practical classes } \\
\text { after completing set of drawings. }\end{array}$ & 83 \\
\hline
\end{tabular}

Table 5: Students' Ideas for the Given Preferences

\begin{tabular}{|l|l|}
\hline \multicolumn{1}{|c|}{ Preference 1 } & \multicolumn{1}{|c|}{ Preference 2 } \\
\hline $\begin{array}{l}\text { Drawings required more time. } \\
\text { Concentration on both written and } \\
\text { drawing questions is difficult at the } \\
\text { end examination. }\end{array}$ & $\begin{array}{l}\text { Information can be clear understood. } \\
\text { Drawing speed can be improved. }\end{array}$ \\
$\begin{array}{l}\text { It is difficult to decide which part } \\
\text { (written or drawing) is to be started } \\
\text { first in the end examination. }\end{array}$ & $\begin{array}{l}\text { More areas can be covered and learned well. } \\
\text { Drawing skill can be improved as } \\
\text { practiced presently. }\end{array}$ \\
\hline
\end{tabular}




\section{RESULTS AND DISCUSSIONS}

\section{Formative Assessment}

Average of 79 students has practiced eight (D1 to D8) manual drawing in the classroom by spending more than 80 hrs. per year and the majority of students have achieved lower performance level. Maximum Students 3, 7 and 5 could receive a higher level score in 2015, 2016 and 2017 respectively, which is not satisfactory at all for 79 students of the group. Though more than 80 hours used for practicing drawings, students did not utilize the given opportunity to improve their skill as expected. Considerable numbers of students have achieved performances for middle and lower levels through practicing drawings from D1 to D8. According to the students' performance on middle level, it is found that students have gradually developed the drafting skill from D1 to D6 in 2015 and 2017, and after D6 their performances have gone down due to certain reasons. A similar pattern is received in 2016 after drawing D5. It is clearly seen that students have shown little interest in learning in the latter part of this process. When comparing performances in lower level, number of students have gone down with this drafting practicing from D1 to D8 as expected in this learning process. Though the better performances has been achieved in the year 2017 by lowering the population after D7, but another two years it is gradually increased. When comparing the students' distribution in both middle and lower level performances, there is a gain from 2015 to 2017 may be due to the effort done by the instructors as they got the training by facilitating students through this process. Instructors have gained experience on facilitating students, especially because they may use effective feedback for students' to learn the drafting.

\section{Summative Assessments}

The variation on students' yearend performance on manual drawings is clearly seen boxplot drawn in Figure 3. There is a gradual improvement in learning and developing skill of manual drafting from 2015 to 2017 may be the effort taken by the instructors during manual drafting practice. In 2016 and 2017, students have scored higher marks than in 2015. Median marks have gradually increased from 35 to 63 and it showed good performance in developing the performances in this teaching system. The range of marks is 47 to 75 covered by $25 \%$ of students in 2015 whereas this marks range has been covered by more than 50\% of students in 2016 and 2017. Students' performances are increased in 2016 and 2017 than in 2015. There is no such improvement to reduce the lower marks for $25 \%$ of students in 2016 and 2017. This learning process has served only to half of the population of students to upgrade their performances towards the middle level category but not to reach the higher level. Though students engaged in this process satisfactorily at the beginning, it is not continued at the later part as expected. The outcome of this result is compared with the students' performance showed in drafting two questions in yearend examination.

\section{Students' Perception on Assessment Method}

The majority of students $(71 \%)$ have mentioned that they prefer separate assessment method for drawing without including them in the written paper. High population (83\%) has given the preference for conducting drawing assessments while practicing manual drawings after set of drawings are completed. Because of this proposed method, students expect benefits such as improving drawing skill and speed, learning in the practical class effectively and gaining more marks at the end. Since considerable time is required to present the correct drawing with satisfactory finishing level, separate time frame for manual drafting will help students to work without struggling for the time. They will manage to complete the work and will show the good performance at the end. 


\section{CONCLUSIONS}

- Students have achieved knowledge and skills which require for manual drawings in building construction technology by practicing them in the classroom with the assistance of instructors from 2015 to 2017. Monitoring students' deskwork and giving feedback are necessary for them to correct their drawings and resubmit till it is completed up to the expected level.

- Performances shown by the students are gradually increased in first four drawings and it is declined in the remaining drawings. Since it happened in all three years in a similar pattern, it needs to be investigated to suggest solutions for better results of this practicing system.

- The majority of students have achieved the minimal requirements of passing the classroom assessments rather than attending the work to get higher grades.

- When comparing the performance of this practice in three continuous years, it is gradually improved from 2015 to 2017 may be due to the effort taken by the instructors. It is clearly understood that, Instructors have received a good training by supervising the students' work, giving feedback and teaching them to attend their mistakes.

- Marks received by the students in the yearend examination of the same three years are gradually improved in par with improving the performance in classroom assessments. Practicing classroom assessments on manual drawing supports for students learning and developing drawing skill to get high marks in the end examination. The system is to be further improved to reduce the lower level grades in both classroom assessments and yearned examination.

- The majority of students (71\%) prefer separate assessment for manual drawing without amalgamating them in the end examination to avoid struggling with time management and concentrate on answering questions. High population of students $(83 \%)$ prefer assessment during the practical class after completion of set of drawings in order to use practical class for effective learning, improving drawing skill, speeding up drawing and finally obtaining high marks for the end examination.

\section{RECOMMENDATION}

- Practicing manual drawings can be used as formative assessments in the classroom to develop drafting skills of students and to improve the knowledge of the relevant subject area.

- Monitoring students' desk work and giving feedback for them to understand their mistakes to attend corrections is necessary to facilitate learning environment in this process.

- Conducting separate summative assessment for manual drawing (without written questions) is helpful for students to answer satisfactorily by managing the allocated time.

\section{FUTURE STUDY}

It is decided to continue this study further to investigate followings.

- Students' interest in learning manual drafting as formative assessment throughout the manual drawing practicing.

- Change of learning style of manual drafting by introducing continuous assessment while practicing them. 
- Effect of learning due to the change (as in 2 above) of formative and summative assessment.

Since the semester system has been introduced to this programme (NDT) and it has been decided to implement continuous assessments, students learning through this new system is be investigated as a research study.

\section{REFERENCES}

1. Bloom, B.S.(1984).The search for methods of instruction as effective as one-to-one tutoring. Educational Leadership, 41 (8), 4 $-17$

2. Braskamp, L.A., \& Ory, J.C. (1994).Assessing faculty work: Enhancing individual and instructional performance,

3. Jossey-Bass Inc. Publishers: San Francisco

4. Buhagiar, M.A. (2007). Classroom assessment within the alternative assessment paradigm: revisiting the territory. The Curriculum Journal.18(1), 39-56https://doi.org/10.1080/09585170701292174

5. Cotton, K. (1988). Monitoring student learning in the classroom. School Improvement Research Series, Office of Educational Research and Improvement, Department of Education, U.S.

6. Eady, M.J., \& Lockyer, L. (2013). Tools for learning: technology and teaching strategies. Learning to teach in the primary school, Queensland University of Technology. Australia, pp 71

7. Gipps, C.V. (1994). Beyond testing: towards a theory of educational assessment: The Falmer Press (A member of the Taylor \& Francis Group), London.

8. Guskey, T.R. (2010). Formative assessment: the contribution of Benjamin S. Boom. In H.L. Andrade \& G.J. Cizek (Eds.) Handbook of formative assessment, New York, Taylor \& Francis, 106-124

9. Hattie, J., \& Timperley, H. (2007).The Power of Feedback. Review of Educational Research, 77 (1), $81-112$ DOI: $10.3102 / 003465430298487$

10. Havnes, A. Smith, K., Dysthe, O. \& Ludvigsen, K. (2012). Formative assessment and feedback: Making learning visible, Studies in Educational Evaluation, 38, 21-27

11. Jones, C.A. (2005).Assessment for learning. Vocational learning Support Programme: published by Learning and Skills development Agency, 16-19

12. Kandamby, G.W.T.C. (2017). Coursework for promoting teaching and learning. International Journal of Higher Education.6(6), 129-138.doi: 10.5430/ijhe.v6n6129

13. Nicol, D. J., \& Macfarlane $\square$ Dick, D. (2006). Formative assessment and self $\square$ regulated learning: a model and seven principles of good feedback practice. Studies in Higher Education. 31(2), 199-218.

https://doi.org/10.1080/03075070600572090.

14. Sadler, D. R. (1989).Formative assessment in the design of instructional systems. Instructional Science, 18, 119-144

15. Smith, Glenn R. Jr. (1997). The comparative effects of manual drafting and computer assisted drafting on secondary students' sectional view and auxiliary view drawings, Theses and Dissertations

16. Srinivasa Rao, A. B., Kumar, P. M., \& Aithal, P. S. (2015). Strategic Planning in Higher Education Institutions: A Case Study of SIMS-VISION 2025.

17. Taghi, J. (2009).The importance of classroom assessment and evaluation in educational system. Proceedings of the 2 nd International Conference of Teaching and Learning, INTI, University College, Malaysia. 
18. Taras, M. (2010). Assessment for learning: assessing the theory and evidence. Procedia Social and Behavioral Sciences 2, 3015-3022.https://doi.org/10.1016/j.sbspro.2010.03.457

19. Thomas A. Angelo, \& Cross. K.P. (1993).A Handbook for College Teachers. 2nd Ed. San Francisco: Jossey-Bass.

20. William, D. (2011). What is assessment for learning? Studies in Educational Evaluation 37, 3-14.

https://doi.org/10.1016/j.stueduc.2011.03.001 
